\title{
UN ÁNGEL POSÓ SU DEDO SOBRE NUESTROS LABIOS
}

\author{
Pablo Perera Velamazán \\ UNED
}

\begin{abstract}
RESUMEN. En la mayor parte de sus casos, la hermenéutica no deja de ser un discursum deudor de la lógica platónico-cristiana de la encarnación, donde, una vez más, mediados "giros lingüísticos", la reducción de "lo que hay" al lenguaje se incauta el cuerpo, corpus, de nuestro habla. De ahí que este pequeño ensayo por medio de la figura del ángel, arquetipo de esta encarnación, dando una vuelta en sentido contrario al habitual al platonismo y al mismo cristianismo, a Tomás de Aquino en concreto, sin abandonarla a su destino establecido, es decir, tratándola como el acaecer de nuestra "carnación", trate de recuperar para el pensar, más allá de cierta reducción de la hermenéutica a método, nuestra condición hermenéutica indisolublemente ligada al cuerpo del discurso.
\end{abstract}

\section{1.}

Se dice, y algo de verdad no puede dejar de haber en ello, que, antes de nuestro nacimiento, antes de que nuestra madre nos dé a la luz de este mundo, hay un ángel, que, al cabo, será nuestro ángel de la guarda (o ángel custodio), que apoya uno de sus dedos, el índice en concreto, sobre nuestros labios que aún se forman, sin estar aún manchados por las palabras, y nos dice al oído, que no conoce de las palabras de los otros sino una vibración acuosa, muy despacio y bajito: "Calla, no digas lo que sabes". De este forzado silencio, tan platónico por otra parte, desde el cual advenimos al mundo sin recordar nada del sitio de donde venimos, no queda más que un testigo físico en nuestro cuerpo recién nacido, como una suerte de reminiscencia, que es la hendidura, huella donde el ángel posó su dedo índice, que parte y reparte nuestro labio superior entre los dos perfiles de nuestro rostro. En cada uno de nosotros, donde esta hendidura se ensancha o se estrecha, se acorta o se alarga, pero en todos por igual, en consecuencia, 
se ha repetido este mismo gesto que, a pesar de manifestarse en medio de un gran silencio, sin querer decir en verdad nada de antemano, nos roba o despoja de nuestro nacimiento como más tarde al fin nos robará o despojará de nuestra muerte. "Calla, no digas lo que sabes», nos susurró a cada uno de nosotros y a todos por igual, singulares cualesquiera, nuestro ángel de la guarda en el mismo momento en que se nos daba a conocer, y en nuestros labios partidos aún resuenan estas palabras cada vez que hablamos, pues, a consecuencia de ello, no podemos sino hablar sobre lo que ya sabemos aunque lo desconozcamos.

Este hablar siempre en nombre de otro que no somos nosotros mismos nos despoja de nuestro nacimiento, decíamos, porque siempre nos presenta en "descendencia de...", porque siempre como tal nacimiento es captado de antemano en una filiación que difumina su acaecer hic et nunc, en un espacio y tiempo tan precisos como singulares. Nos estamos refiriendo a la "lógica angélica» que ha regido implacablemente la anunciación del sentido en nuestro siempre-ya perdido Occidente. Puesto que somos antes que nada "hijos" de ese saber que no podemos saber, nuestro cuerpo deviene signo, al modo de la huella que rompe nuestros labios superiores, de un sentido donde su extensión, su acaecer sin más, es expulsado hacia su propio interior, hasta el límite en el que el signo-cuerpo es abolido en la presencia que representaba sin recordarlo. Nuestra encarnación, en este sentido, es una descorporeización, pues importa muy poco que estemos aquí o allí, que seamos el aquí o ahí de un lugar. Lo importante es que sólo estamos aquí en cuanto vicarios de un sentido, encarnando la absoluta contradicción de no poder ser cuerpo sin serlo de un espíritu que, a través de las palabras del ángel que siempre lo vinculan a una procedencia y precedencia del sentido, lo desincorpora.

Y cuando desde ese silencio en que nacemos se atisba un roce peculiar del aire en nuestra garganta, un roce como nunca ha habido ni habrá otro, cuando lloramos o reímos, o gemimos, o gritamos, o dejamos, al cabo, que la primera palabra brote en la punta de nuestra lengua, antes de poder atender demasiado a ello, según esta lógica de un sentido que siempre se anuncia en su distancia, se nos vuelve a aparecer ese ángel de la guarda que se nos ha asignado a cada uno de nosotros en el momento mismo de nuestra concepción. Son ellos los encargados de velar por nosotros en cuanto que nos protegen de los peligros o, más bien, del peligro de olvidarnos de ese olvido primordial que nos susurra a cada vez que el sentido no está sin más en las palabras que pronunciamos en nuestra 
voz singular. "Yo voy a enviar un ángel delante de ti, para que te proteja en el camino y te conduzca hasta el lugar que te he preparado. Respétalo y escucha su voz. No te rebeles contra él, porque no les perdonará las transgresiones, ya que mi Nombre está en él. Si tú escuchas realmente su voz y haces todo lo que yo te diga, seré enemigo de tus enemigos y adversario de tus adversarios. Entonces mi ángel irá delante de ti” (Éxodo, 23, 20-23a). Y siempre delante de nosotros irán, en consecuencia, anticipándonos un sentido que nunca está donde somos y que siempre reenvía nuestro ser aquí, nuestra finitud y contingencia, hacia un más allá, hacia una infinitud que la constituye como tal, como una finitud derivada. Como dice el Himno de la Liturgia de las Horas: «Aunque espíritu invisible,/ sé que te hallas a mi lado,/ escuchas mis oraciones/ y cuentas todos mis pasos».

«Guardaos de menospreciar a estos pequeños» (Mateo, 18,10), parece haber sido uno de los cuidados insistentes de nuestro Occidente. No sólo los cuerpos metafísicos o teológicos de nuestra tradición se han acompañado de esta vocación, sino, sin ir más lejos, en los bordes de nuestro tiempo, cuando no parecen caber ya ni metafísica ni teología, los cuerpos fenomenológicos, psicoanalíticos, semiológicos o hermenéuticos que nos acompañan por doquier no dejan de hacer suya la antes comentada contradicción de no poder ser el cuerpo (o corpus) que son sin serlo de un espíritu que lo desincorpora, llámese como se llame a este espíritu (intención, significante o tradición). Y decimos "parece haber sido" porque, sobre ese mismo borde sobre el que nuestro tiempo se nos presenta, más allá de estos discursos que nos hablan acerca de un sentido que no es más que su retorno y consiguiente proyección, de un sentido que no es más que su deseo o ficción, los cuerpos, nuestros cuerpos, hoy, hic et nunc, se nos presentan más acá de todo significado, ya ni siquiera como cuerpos objetivados o alienados, como el viejo marxismo quería, sino como cuerpos que pesan y se sopesan más allá de cualquier significación, extraños y desnudos, donde nuestro propio cuerpo, tu cuerpo, aquel cuerpo, su cuerpo, sólo se expone formando parte, también extraño y desnudo, de un mundo que no deviene otra cosa sino su población, la conjunción indistinta y numerosa de nuestros cuerpos, siempre, al borde, pues, de lo inmundo.

Pero, por ello mismo, tal vez sólo sea en nuestro mundo, siempre al borde de lo inmundo, como finitud que se cierra sobre sí misma, donde puede ser apreciada en verdad la presencia de los ángeles, esos pequeños, hemos dicho, que no debemos menospreciar. No en vano, allí donde la filosofía o el arte han experi- 
mentado consigo mismos, con su propia decisión en cuanto tales, es decir, a costa de sí mismos como saber o simple gusto en disputa, en relación con la figura del ángel (aunque ni siquiera haya sido nombrado así), a través de ella se han expuesto siempre a la lógica de un sentido que no pertenece sin más a su acaecer finito o inmanente, como de por sí es evidente en su caracterización como mensajero de un sentido que no simplemente está aquí, pero que tampoco pertenece, como en principio cabría suponer, a su remisión a un infinito trascendente, que haría de ese sentido un siempre estar más allá. Y es, precisamente, esta relación con el sentido, ni inmanente ni trascendente, pero siendo ambas a la vez, en su expropiación mutua, a favor de un sentido "trans-inmanente», si es que se puede decir así, la única (y nos afirmamos una y mil veces sobre esto) relación que cabe a favor de nuestro presente, de la realidad que en él nos convoca, de nuestro "mundo de los cuerpos», y no en contra suyo y a favor de su irrealización como todos los anteriormente citados discursos de la significación hacen.

Sólo ha bastado que, en el extremo más fino del pensamiento, este nuestro ser siempre-ya en el sentido que nos constituye, no haya sido reducido por los rigores o debilidades de una interpretación que busca recobrar ese sentido ya perdido o, al menos, identificarse con su búsqueda infinita, y dar un paso hacia atrás que suponga al cabo un gran salto hacia delante. Porque, en suma, en todos estos pensamientos de la significación, se trata, a pesar de lo que se diga, de forzar ese olvido ("Calla, no digas lo que sabes»), de olvidarse de él, y suturar sea como sea la hendidura que parte nuestros labios superiores y donde nuestra voz, la tuya, la suya, la mía, la nuestra, a cada vez que una palabra se cae de la punta de nuestra lengua, se quiebra en la singularidad de su propia tesitura. Pero nuestros labios siempre están partidos, como los de nuestros padres y los de nuestros hijos, y no hay sutura que pueda cerrar para siempre su herida. Así, en ese extremo más fino del pensamiento, como antes he dicho, se ha podido volver a escuchar sus palabras ("Calla, no digas lo que sabes"), y no se ha dejado de volver a posar el dedo índice, ahora ya el nuestro, y acariciar, despacio y muy bajito, en la hendidura de nuestros labios. Pues, allí donde nuestro ángel de la guarda, ya muerto Dios, nos ha seguido acompañando, disfrazado extrañamente de Hermes, hay quien no ha podido, o se ha resistido, dar ningún significado a sus palabras, o al menos no lo ha podido hacer al margen de su forma de presentarse, Hermes, el mensajero de una palabra que no es suya, al margen de su aspecto, de su estilo, del tono de su voz, de su propia relación con el contenido del mensaje (que puede no conocer, o no comprender), que contamina su significación, que afecta al signi- 
ficado, como por sus bordes, y sin remedio. Y este no poder decir lo que ya se sabe que nuestro ángel de la guarda nos susurró antes de nacer, que no es otra cosa sino que nuestro nacimiento sólo cabe porque estamos previamente en el sentido, nuestra condición hermenéutica, en definitiva, y que sólo se expone en la presencia siempre singular de una voz, la tuya, la suya, la mía, la nuestra, en cuanto mensaje de lo divino que no deja de ser, no se cierra sin más en esta singularidad sin abrirse al mismo tiempo convocando a través de ella la partición de voces que el Lógos es. Ahí estamos todos, miradnos bien, con el labio partido entre los dos perfiles de nuestro rostro.

Algo de experimento a favor de lo dicho tiene el Tratado sobre los ángeles en el seno de la Suma teológica donde Tomás de Aquino estudia el origen y la naturaleza de estos extraños seres a mitad de camino entre la contingencia o finitud relativa de lo humano, cuya existencia sólo cabe en cuanto actualización de una esencia, y la absoluta necesidad de lo divino donde esencia y existencia coinciden. Ciertamente, pocos son los teólogos y menos los filósofos que han apreciado este hermoso tratado de "el doctor angélico" acerca de los ángeles. De igual manera que, por un lado, se afirma que la revelación divina poco nos dice acerca de ellos, poco también puede, por el otro, hacer la pura razón para tratarse con la peculiaridad de su existir. A pesar de todo, sin embargo, difícilmente se puede ocultar las muchas veces que Tomás de Aquino, "el doctor angélico", insistimos, se ocupa de estas extrañas y bellas creaturas (en sus diversos comentarios sobre la Sagrada Escritura y en la Suma contra gentiles, en las Cuestiones disputadas, en De veritate, en De potentia...).

Después de la bondad divina, afirma el Aquinate, que es un fin independiente de las cosas, el principal bien que existe y convoca al conjunto de las creaturas es la perfección del universo, que no existiría si en el mundo no se encontrasen todos los grados del ser. Por tanto, si corresponde a la Providencia divina producir el ser en todos sus grados, y uno de estos grados debe ser el entender, que no puede ser acto del cuerpo ni de nada corpóreo, se plantea, en consecuencia, que deberán existir seres intelectuales perfectamente espirituales e incorpóreos que no son otros sino aquellos a los que llamamos ángeles. De esta manera, los ángeles, por un lado, detentan en su naturaleza el supremo grado de perfección 
entre todas las creaturas, son los más nobles efectos de la creación. Pero, por otro, no dejan de ser creaturas y de, por ello, estar condicionados por su relación con las otras creaturas. Así, afirma "el doctor angélico", su existir se ordena a formar parte del universo y a entrar en el gobierno y servicio de las cosas corpóreas, tanto de las inferiores como del hombre, que a su vez participa de su naturaleza espiritual y de la de los cuerpos físicos. La interdependencia de las creaturas, un mundo que no es otra cosa sino esta relación, forma parte del plan de Dios. El sol y la luna, el cedro y la flor, el águila y el gorrión... las diversidades y desigualdades demuestran que ninguna creatura se basta por sí misma y que sólo existen dependientes unas de otras para complementarse y servirse mutuamente, y los ángeles, aún siendo seres intelectuales perfectamente espirituales, no están exentos de ello.

Aunque, precisamente por esta su especial naturaleza, ni puramente corporal ni compuesta, sino puramente espiritual, son ellos, los ángeles, los que por su perfección se acercan más a la naturaleza divina y son los que mejor representan a Dios, razón por la cual son sus mensajeros predilectos, el mejor medio para conocerle de un modo menos imperfecto. "Si conviene que antes de lo imperfecto en algún género exista lo perfecto, es conveniente que, antes de las almas humanas, que entienden mediante los accidentes, existan algunas substancias intelectuales que entiendan las cosas que son en sí inteligibles, y que no reciban su conocimiento a través de los sentidos y, por consiguiente, totalmente separadas de los cuerpos", afirma el Aquinate. Así, mientras que nuestro entendimiento se presenta siempre como un mendigo de los sentidos, en su operación propia dependiente extrínsecamente del cuerpo, el ángel, en cambio, como una naturaleza más perfecta creada como sustancia completa y espiritual, de un solo golpe intuitivo ve la verdad y ésta queda grabada en su memoria de manera indeleble.

Dicho esto, nada al margen de los discursos de descorporeización de la lógica angélica parece que encontremos en el argumento de Tomás de Aquino. Sin embargo, si prestamos un poco más de atención observamos cómo sobre él se precipitan cuestiones que nos permiten presentar este Tratado sobre los ángeles como un experimento sin verdad (que, propio de la filosofía o del arte, y a diferencia de los experimentos científicos, no tienen como fin la verificación o falsación de alguna hipótesis, sino que se cuestionan el ser mismo) donde «el doctor angélico» expone un cierto trato con el sentido en un mundo donde lo primero 
que se da es la relación, con un mundo que, en definitiva, no es más que esta relación entre los seres que lo configuran. Por eso no puede dejar de hacer suyas las afirmaciones de Agustín de Hipona según las cuales los ángeles no lo son tanto por ser puros espíritus o substancias intelectuales, como se suele decir, sino, sobre todo, por ser los enviados o mensajeros donde se hace patente el orden de perfección donde se cumple la efectuación del mundo como mundo según la lógica de la relación antes citada. Después de ocuparse en su Suma teológica del aquí y ahora, hic et nunc, de la realidad de lo humano, los ángeles se presentan para «el doctor angélico" como los intermediarios necesarios entre Dios y los hombres, a través de los cuales, en cuanto que su naturaleza no es más que su oficio, su ser mensajeros, se trasciende hacia un siempre-más-allá del ser aquí del hombre.

De ahí que Tomás de Aquino insista en que «no hay por qué hablar de que el ángel sea medido por el lugar ni de que ocupe un sitio en lo extenso, ya que éstas son cosas peculiares del cuerpo localizado". Un ángel, afirma, puede en un determinado instante estar en un lugar, y en otro instante en otro, sin necesidad de que entre ellos medie tiempo alguno, pues también "están por encima del tiempo que mide el movimiento del cielo", sobre todos los movimientos, en suma, de la creatura corporal. Sin embargo, en cuanto creaturas dependientes de Dios, aún representando el más allá que trasciende y da sentido al hic et nunc de lo humano, el ángel «no está por encima del tiempo que mide la sucesión de su ser después de no ser, ni del que mide la sucesión que hay en sus operaciones", es decir, en él se pone en juego más que un tiempo crónico que afecta y modifica a las sustancias, el tiempo aiónico según el cual hay algo, las sustancias, que se da, en vez de no darse, donde este darse coincide con un acaecer a la presencia, con una aparición, más que con un presentarse como presencia o apariencia de un sentido que no está ahí. Todo lo cual quiere decir que entre la absoluta necesidad de Dios y la contingencia relativa de lo humano, donde la existencia sólo cabe como un acto de ser, entre el ser que coincide con su sentido y el ser que nunca es donde está, la figura del ángel pone en juego una existencia donde la contingencia, no remitida nunca a su simple acaecer finito, es puesta fuera de sí como lo que pone fuera de sí toda contingencia, es decir, el sentido que es relación y tránsito entre todos los seres creados, haciéndose con ello, en última instancia, una contingencia absoluta y necesaria.

Como ocurre siempre con estos "experimentos sin verdad" en los que se emplea la filosofía al ras de su decisión como filosofía, el experimento que es el 
Tratado sobre los ángeles de Tomás de Aquino no remite al ser o no ser en acto de algo, Dios u hombre, acerca de los cuales en consecuencia siempre cabría alguna verdad por decir, sino a su ser en potencia que, en cuanto puede ser o no ser, se substrae a toda condición de verdad, y nos pone en relación con esta contingencia absoluta. Y es en este punto donde el Aquinate deviene «el doctor angélico", pues quien se arriesga a este tipo de experimentos lo que hace, antes que nada, en consecuencia, es comprometer su "propio modo de existir" en relación con esta contingencia absoluta, que es, por otra parte, lo que siempre han hecho la filosofía y el arte en cuanto tales. Como cuando Avicena, recuerda Giogio Agamben en Bartleby o de la contingencia, propone su experimento del «hombre volador» y desmembra y desorganiza parte por parte el cuerpo de un hombre porque desea probar que, aún fragmentado y suspendido en el aire, podría aún decir «soy», que el existente puro es la experiencia de un cuerpo sin partes ni órganos, o cuando Heidegger sustituye el yo psicosomático por un ser vacío e inesencial que no es otra cosa que sus modos de ser y que sólo alcanza la posibilidad en la imposibilidad, o cuando Deleuze relee a Foucault a través de su concepto de «hombre infame» como un singular cualquiera que a veces denomina "autómata espiritual»... Así, por retomar de nuevo nuestro camino, en el seno de la Suma teológica, aunque sea a pesar suyo, allí donde el filósofo mismo deviene mensajero del sentido, se pone en juego una mutación, aberrante en apariencia, pero que, convertida en un principio a seguir, acaba transformando el trato con el sentido. En este Tratado sobre los ángeles el Aquinate, podríamos decir, se revela una vez más el proceso imparable de deconstrucción al que el mismo cristianismo se ha sometido desde sus propios principios (ese extraño principio que nos habla de un mundo creado a partir de la nada por Dios con el que Dios mismo acaba confundiéndose) hasta dar lugar al acaecer de la mundanización de nuestro mundo antes comentada en la forma de la "población de los cuerpos".

No en vano, ese ángel de la guarda que posó su dedo sobre nuestros labios trascendiendo el acaecer finito de nuestro nacimiento es, al cabo, entre todos los ángeles, al acompañarnos en cada uno de nuestros pasos, quien cuida con más esmero de nuestro "aquí y ahora». Un cuidado que no consiste, según lo que hemos dicho desde Tomás de Aquino, en negarlo como "aquí y ahora» a favor de algún estado o condición que le dé sentido (si hay algo que caracteriza al cristianismo en su devenir ateo es que el único dato previo que pone en juego es el don creador de Dios, es decir, el mundo recibido por el hombre, que deviene con ello más copartícipe de la historia que mero recipiendario, y nunca un estado o 
condición previa que se deba actualizar), sino en afirmarlo como "aquí y ahora" en su relación conjunta, pero expropiante (es decir, poniendo fuera de sí toda finitud), con los "otros aquí y ahora" con los que está en relación configurando un mundo, nuestro mundo. Es en este sentido en el que aún podemos decir que tenemos los labios partidos, ya al margen de toda escena teológica, pero también de toda ideología de la secularización, porque, afortunadamente, nunca nacemos solos ni somos dueños de nuestro nacimiento, como tampoco morimos solos ni somos dueños de nuestra muerte. Siempre nacemos y morimos entre otros, y lo hacemos singularmente, cada uno con nuestro propio tono y tesitura de voz, y es, precisamente, nuestro ángel de la guarda quien, habiéndonos partido el labio, nos recuerda, ahora sí y al margen de toda la lógica de la encarnación, que el sentido siempre, en cuanto partido, está compartido entre todos nosotros, y que sólo podemos cuidarnos de nosotros mismos cuidándonos de su ser en común.

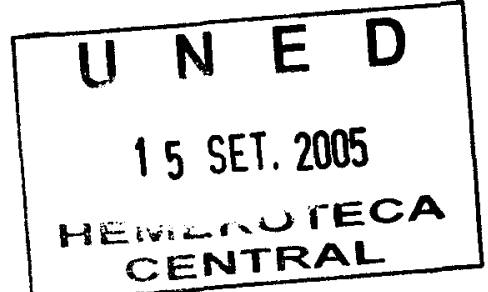

